\title{
Multistress characterization of fault mechanisms in aerospace electric actuators
}

\author{
D. Barater, F. Immovilli, A. Soldati, G. Buticchi, G. Franceschini, C. Gerada, M. Galea
}

\begin{abstract}
The concept behind the More Electric Aircraft (MEA) is the progressive electrification of on-board actuators and services. It is a way to reduce or eliminate the dependence on hydraulic, mechanical and the bleed air/pneumatic systems and pursue efficiency, reliability and maintainability. This paper presents a specialised test rig whose main objective is to assess insulation lifespan modelling under various stress conditions, especially investigating the interaction between ageing factors. The test set-up is able to reproduce a multitude of environmental and operational conditions at which electric drives and motors, used in aerospace applications, are subjected. It is thus possible to tailor the test cycle in order to mimic the working cycle of an electrical motor during real operation in aircraft application. The developed test-rig is aimed at projecting the technology readiness to higher levels of maturity, in the context of electrical motors and drives for aerospace applications. Its other objective is to validate and support the development of a comprehensive insulation degradation model.
\end{abstract}

Keywords-MEA; Electrical fault detection; PoF; lifetime modeling

\section{INTRODUCTION}

The concepts of the All Electric Aircraft (AEA) and More Electric Aircraft (MEA) have been debated and developed over the past thirty years. The progressive electrification of on-board services is a way to reduce or eliminate the dependence on hydraulic, mechanical and the bleed air/pneumatic systems for the sake of efficiency and reliability.

The concept of MEA involves the introduction of electromechanical actuators and electrohydraulic actuators of flight surfaces for wide-body aircraft, moving from the "fly-by wire" to the "power-by wire" concept. Safety and reliability are the main drivers of the aerospace industry. Specific requirements in terms of compactness, reliability, fault propagation, harsh ambient conditions and standard compliance, poses real challenges to the design and material

D. Barater, A. Soldati and G. Franceschini are with the Department of Information Engineering, University of Parma, Italy. davide.barater@unipr.it

F. Immowilli is with DISMI - University of Modena and Reggio

Emilia, Reggio Emilia, Italy. fabio.immovilli@unimore.it

G. Buticchi is with the Chair of Power Electronics, University of

Kiel, Germany.gibu@tf.uni-kiel.de

M. Galea and C. Gerada are with PEMC Group, The University of Nottingham, UK. michael.galea@nottingham.ac.uk,

chris.gerada@nottingham.ac.uk choices. Because of the aforementioned constraints, the materials must be well characterized, as there is no space for over-engineered solutions.

Recent research has already brought to the development of many electric drives that are now installed in large more electric civil aircrafts, such as the Airbus A380 and Boeing's 787 Dreamliner, which are the main commercial aircraft, that have fully embraced the MEA concept.

As more electric technologies move forward, there is a perceived pull towards the use of higher voltages, due to the continuous increase of the electrical on-board power demand due to the MEA concept. However, the use of higher phase voltage does require considerable care during design to avoid the onset of partial discharge and corona effect, especially at high altitudes.

In this context, a multitude of electric drives, generators and electromechanical actuators can be identified. Depending on their specific function, the characteristics, ratings and service condition can be extremely variable. This becomes evident especially when taking into account a typical mission profile: take-off, cruise and landing. An overview of the main functions and expected service condition during mission profile is summarized in Table I.

Electro Mechanical Actuators (EMA) are safety-critical components of an aerospace system and an undetected actuator failure can lead to serious consequences. EMA fault diagnosis poses an interesting research problem as it is composed of electrical, electronic, and mechanical subsystems, which results in intricate failure modes and effects. Any fault in these sub-assemblies needs to be successfully, and efficiently detected, identified, using a limited set of sensor signals available [1] while also avoiding false positive caused by environmental noise related to operating conditions [2].

It is also evident that a lifetime prediction model should take into account a multitude of stress factors and use case conditions. The traditional approach was the quantitative reliability prediction based on empirical data and various handbooks on reliability released by military and industry, reporting the Mean Time between Failure (MTBF) of a given component or system [3]. The approach was based on empirical data and statistical analysis, aiming to evaluate the Mean Time between Failure (MTBF) of a given component or system.

A more recent approach focuses on identifying and modelling of the physical causes of component failure. This is the basic 
TABLE I. AirCRAFT EleCtric ACtUATOR SERVICE CONDITIONS

\begin{tabular}{|l|c|c|l|c|}
\hline \multicolumn{1}{|c|}{ Component } & Service rating & $\begin{array}{c}\text { Overload } \\
\text { capacity }\end{array}$ & \multicolumn{1}{|c|}{ Main source of stress } & Mission profile critical phases \\
\hline Starter-Alternator & continuous & Mild & Temperature high & take-off, cruise, landing \\
\hline $\begin{array}{l}\text { Engine ancillaries (fuel, oil } \\
\text { pumps) }\end{array}$ & continuous & Mild & Temperature high & \multicolumn{1}{c|}{ take-off, cruise, landing } \\
\hline Control surfaces actuators & continuous & Heavy & $\begin{array}{l}\text { Temperature low } \\
\text { Moisture - Icing }\end{array}$ \\
\hline Landing gear actuators & intermittent landing \\
\hline $\begin{array}{l}\text { In-wheel motor for green } \\
\text { taxiing }\end{array}$ & intermittent & Mild & $\begin{array}{l}\text { Moisture - Icing } \\
\text { Shock-vibrations }\end{array}$ & take-off, landing \\
\hline Cabin pressurization & continuous & $\begin{array}{l}\text { Temperature swing } \\
\text { Shock-vibrations } \\
\text { Electromechanical }\end{array}$ & take-off, cruise, landing \\
\hline
\end{tabular}

concept of the Physics Of Failure (PoF) [4], that changes the analysis of system from a "box of components" to a "box of failure mechanisms" [5]. The PoF approach analyses and models each failure mechanism induced by environmental and usage stresses. The PoF is a methodology based on root-cause failure mechanism analysis and the impact of materials, defects, and stresses on product reliability [6].

However, it is not guaranteed that, for given component, with a well-modelled failure mechanism, the process of failure would be exactly the same at system level, since many cross interactions, that cannot be considered at component level, are instead fully present at system level [7], together with manufacturing or assembly faults [8]

The traditional handbook-based reliability prediction provides failure rate models for various components. The PoF approach analyses and models each failure mechanism induced by environmental and usage stresses. For a given component, there could be multiple failure mechanisms, which should be identified individually. In addition, failure mechanisms are not limited to the component level.

As it can be expected, the integration of different models, related to different failure mechanisms, into a unique model,

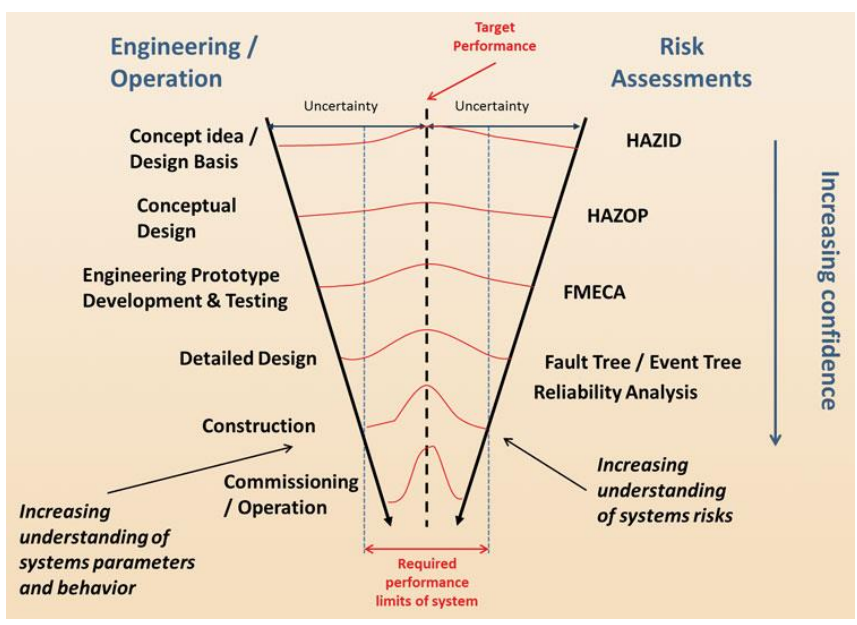

Fig. 1 Schematic of risk assessment / reliability analysis. taking into account all the physical processes and stress factors involving in a given component fault, is not an easy task. From this prospective, it is challengeable to apply the PoF to a complex system of which limited number of models and their associated parameters are available [6].

For all these issues, PoF have not yet reached a complete maturity and Hybrid approach, taking into account empirical statistical measures integrated with some physical analysis, are currently preferred.

In fact, whereas predictions were mainly based on empirical data at the beginning (MIL-HDBK- 217), more recently attempts have been made to incorporate some form of physics of failure [9], such as in MIL217+, FIDES.

Among the different causes of failures reported, studies revealed that approximately $30 \%$ of the failures are related to electrical faults [10]. Since the majority of electrical fault happens in stator or rotor windings insulation, the design of the insulation and winding structure plays a major role on the possible failure mechanisms. In fact, there are two basic winding structure: Random-wound and Form-wound. Traditionally in industry applications, random-wound stators are typically used for sub-Megawatt machines. In this construction turns near the motor contacts can be placed against turns near to the winding neutral point: in inverter-fed motors, high dv/dt can be seen between adjacent turns, increasing the chances to trigger partial discharge phenomena. Form-wound stators are usually intended for multi-Megawatt machines operating at $1000 \mathrm{~V}$ and above, and careful design and manufacture are used to ensure that each turn in a coil is adjacent to another turn with the smallest possible voltage difference. For transport applications, many automotive and aerospace electric machines employ Form-Wound windings. This is especially the case for concentrated-wound, sectorconstructed machines and in high reliability multiphase electric drives [11]. Each of the components constituting the winding insulation system must be properly designed to withstand ambient, electrical, thermal and mechanical operating conditions. Each of them is subject to aging due the repeated exposition to different stress factors that can weaken 
their insulation properties and trigger different fault mechanisms.

In this scenario, opportunities related to a specialized test platform for assessing the impact of electrical motor aging factors under various stress conditions is extremely important. This work describes a setup that aims at re-creating the typical aircraft operating condition of an electric drive system. The final objective is to test the technology-readiness level of the electric drive, giving a feedback to the designer, in order to improve the overall system's reliability. This work was firstly proposed in [12] and it here revised, enriched with new experimental validations and considerations.

\section{MUltistRess InSUlation AGING FACTORS}

The breakdown of the stator insulation system is usually a slowly developing process, which at first leads to deterioration of the turn-turn insulation and finally to phase-to-phase or phase-to-ground insulation respectively. The detection of a change in the insulation state provides the possibility to track insulation deterioration and, in field applications, intervene with strategic maintenance to prevent an abrupt breakdown. Offline insulation monitoring methods, which are often described in literature [13] and standards [14] with the aim of detecting insulation degradation, have in common that the applicability is complex and special equipment is needed. Moreover, a single diagnostic test alone is not able to predict the remaining lifetime. Even when using several diagnostic methods together there are areas of uncertainty in the estimation of insulation lifetime and a lifetime super-model is advisable.

The lifetime model should ideally combine information from past use as well as expected future use to better estimate the remaining lifetime of the actuator [15]. A schematic block diagram for the lifetime estimation of stator windings is presented in Fig. 2.

The expected remaining lifetime is determined by taking into consideration the future operation mode along with the current and past operation conditions. Lifetime estimation procedures can also include simulation of various future

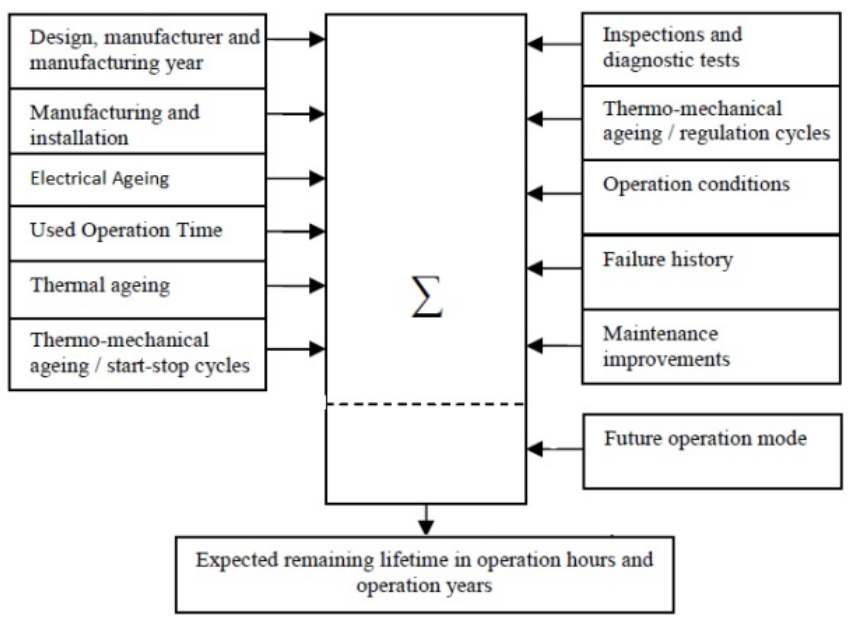

Fig. 2 Schematic flowchart for lifetime estimation of stator windings operation mode scenarios, if needed. The target of the lifetime estimation is to maximize the lifetime but also to still keep enough risk tolerance to prevent major failures from happening in the near future.

The developed experimental setup allows to experimentally investigate the effects of four major sources of stress in winding insulation (both as single effects as well as combined).

Taking into account aerospace application, ambient stresses that are normally neglected in everyday motor applications, such as air pressure, are rather responsible to accelerate insulation degradation. The factors that are considered significant for lifespan reduction and will be subjected to investigation are listed below:

- Electrical: In inverter fed applications, voltage, frequency and voltage rise time. High dv/dt, applied between adjacent turns in inverter-fed motors, increases the chances to trigger partial discharge phenomena [16].

- Ambient: pressure and humidity. Partial discharge and corona effect are indeed enhanced by low pressure associated to high altitudes: as pressure is reduced, the voltage required to initiate partial discharge is also reduced, down to Paschen's minimum [17]. Moisture can be absorbed and penetrate into insulation slots or cavities, causing an overall decrease of the dielectric strength. An increase of PD activity and treeing effect are likely to be observed. Insulation resistance (IR) and polarization index (PI) are probably the most widely used diagnostic test in order to detect contamination and moisture problems on machine windings [18].

- Thermal: Thermal deterioration is probably one of the most common reasons of stator windings failure and effective solutions to enhance the thermal characteristics of the windings has been extensively investigated over the years [19]. It is essentially an oxidation chemical reaction [20], that can be modelled with exponential Arrhenius law.

- Thermo-mechanical: Thermal cycling of coils, i.e. repetitive alternate raising and lowering of the temperature, subjects the insulation system of coils to thermo-mechanical stress which can degrade the turn-to-turn and groundwall insulation [21], [22], [23].

Usually tests are not conducted on actual machines, but are instead performed on special coil specimens that are intended to model the machine's coil insulation system. Formettes are specially manufactured coils with turn and ground insulation, which are mounted on a frame simulating a portion of the stator core. For random-wound stator windings, tests are performed using a "motorette" consisting of model coils installed in a simulated slot.

\section{DESIGN OF EXPERIMENT AND PROPOSED TEST RIG}

The "one factor at a time" (OFAT) is a method of designing and conduction experiments involving the testing of factors, and causes, one at a time with the aim of separating their effects. 
OFAT can be time consuming if a comprehensive series of experiments is conducted, and it is only valid when no interactions exist between factors. Design of experiment (DOE) is a planned approach for determining cause and effect relationships that can be applied to any process with measurable inputs and outputs. Data processing of test results can also generate lifetime models [24]. It is particularly helpful to identify which factors have the highest ageing effect and, more important, if there is any interaction between them that speed up insulation degradation up to failure. One of the most difficult decisions for DOE, aside from the choice of stress factors to investigate, is how many levels take into account. Two level designs are typical in practice because this is the lowest level designs that meet the basic criteria of designs. The main drawback of two level designs is that it can only describe linear relationship.

The proposed test setup, is able to investigate lifespan modelling under various stress conditions, including coupling effects between the factors. Among other factors, the test bed will allow to characterize insulation degradation under variable ambient and power supply parameters, from simple models such as twisted pairs, up to pre-formed coils and even complete machines at rated load under mission profile.

The test setup comprises a thermal vacuum chamber, an embedded dynamometer/brake system and a custom inverter based on SiC devices capable to apply PWM commutation of different $\mathrm{dv} / \mathrm{dt}$ ratio. The all-in-one approach, illustrated in Fig. 3, thus allows for comprehensive, accelerated lifeconsumption tests and procedures, custom designed according to specific operational mission profiles. The achieved data will be critical to inform the design process of the next generation drive and will facilitate a considerable reduction of overengineering, synonymous with traditional design procedures.

The test-rig will be able to validate and justify the development of comprehensive models to describe fault mechanism in electrical motors (i.e. insulation degradation of the motor windings). The test setup will provide the facility to simultaneously assess different degradation mechanisms, with the main advantage of evaluating interactions between different stress factors.

With such a unique set-up, it is the authors' objective to achieve a step-change in the development of electrical drives and machines. This is particularly true in the context of technology readiness levels (TRL). This facility will permit to close the gap between the different TRLs, in the sense that it will permit much faster and much more accurate iterations between the different development levels at component level

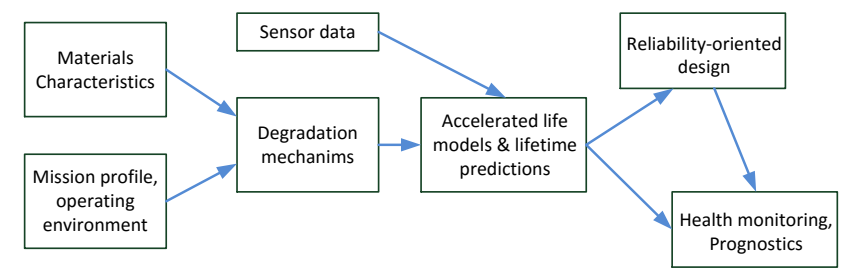

Fig. 3 Reliability oriented design workflow. (converter, machine or control), but more importantly at system level (electrical drive). This facility will also under-pin the on-going push towards multi-physical design and implementation of systems.

\section{A. Architecture of the Proposed Test Rig}

The rig provides the facility to test different degradation mechanisms at the same time, with the main advantage being the ability to reproduce and evaluate the cross-couplings between the various ageing mechanisms. Moreover, the test setup allows the execution of very specific accelerated lifetime tests, tailored on the selected mission profile.

The test rig is able to reproduce a broad selection of environmental and operational conditions at which electric drives and motors, used in aerospace applications, are subject. The system also permits to stimulate the electric motors under test with different or combined environmental and electric stress factors, acquire data from the motor/drive during the test procedures, and support the experimental validation and fine tuning of life-time models predicting fault mechanisms in electric motors for aerospace applications.

The test rig comprises four main components: a Thermal vacuum chamber to apply environmental stress factors; a reconfigurable test bench that can be embedded in the test chamber; a data acquisition and control system to monitor an acquire relevant operating parameters and a custom inverter to drive the motor under test (MUT) while applying different levels of stress. Each subsystem will be detailed in the following, while the custom inverter (MUT converter) will be presented in the next section.

With reference to Fig. 4, the test bench frame (7) hosts the motor under test (2), the custom test inverter (5), the brake (4) and its drive (6). In order to facilitate the set-up procedures for different types of motors under test, a vacuum tight bulkhead (8) will be integrated into the structure of the test bench. Rails will guide the insertionlextraction of the motor under test intolfrom the thermal vacuum chamber (1). In this way, it will be possible cabling and setting up of the MUT outside the thermal chamber, allowing for easy handling by the technicians, favoring the safety and speeding up the entire

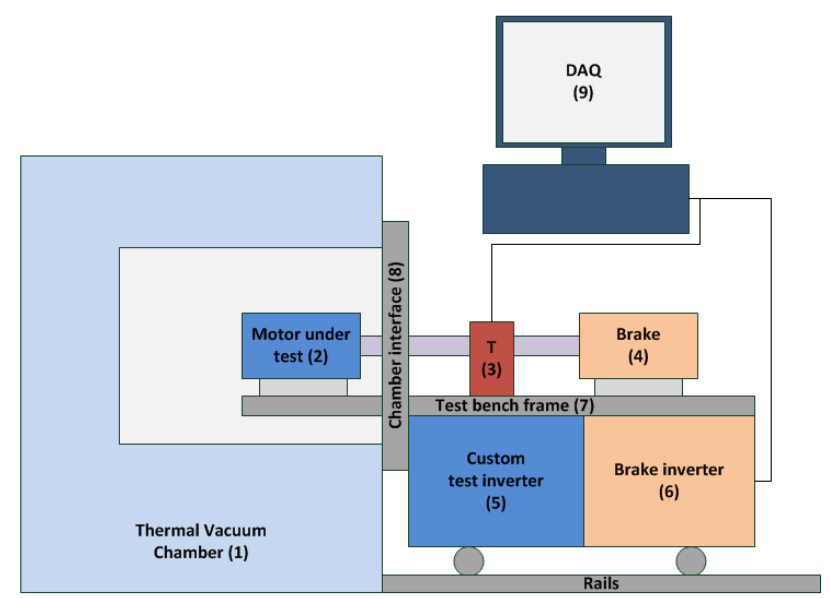

Fig. 4 Simplified schematic of the test bed. 
process.

The specifications for the test rig components are resumed in Table II. The test bench structure is completely selfcontained: it features a cantilevered construction, to support the MUT and allow its placement inside the thermal vacuum chamber without placing stresses on the chamber frame/walls (see Fig. 5). Access to the test volume is given by an ISO-K flange DN320 that can accommodate MUT with body diameter up to $250 \mathrm{~mm}$. The flange and mating metal bellows ensure air tightness, Fig. 6. The test bench bulkhead incorporates a high-speed shaft seal, that provide an airtight passage for the shaft from the test volume inside the thermal vacuum chamber and the dynamometer section housed outside at room pressure \& temperature. Another four ISO-K flanges DN100 provide feedthrough for the shielded power cable to the MUT, together with various feedback (encoder/resolver) and transducer couplings (thermocouple, accelerometers) by means of MIL spec connectors.

TABLE II. TEST RIG COMPONENTS SUMMARY

\begin{tabular}{|c|c|}
\hline Component & Specifications \\
\hline $\begin{array}{l}\text { Thermal } \\
\text { Vacuum } \\
\text { Chamber }\end{array}$ & $\begin{array}{l}\text { Temperature: }-40+180{ }^{\circ} \mathrm{C} \\
\text { Pressure: } 30-1000 \mathrm{mBar} \text { (from sea level to } 50000 \mathrm{ft} \text { ) } \\
\text { Power handling capability - thermal: } 4 \mathrm{~kW} \text { (with } \mathrm{P}>300 \\
\text { mBar) }\end{array}$ \\
\hline $\begin{array}{l}\text { Motor Test } \\
\text { bench }\end{array}$ & $\begin{array}{l}\text { Comprises fixture for the torque meter, test \& brake motors } \\
\text { High speed face seal for the passage of the motor shaft } \\
\text { Mounted on rails for insertion in the test chamber } \\
\text { Brake: liquid-cooled high speed spindle motor } \\
\text { High speed contactless flange torque meter }\end{array}$ \\
\hline $\begin{array}{l}\text { Data } \\
\text { acquisition } \\
\text { and control }\end{array}$ & $\begin{array}{l}\text { Control of the Vacuum thermal chamber parameters } \\
\text { Control of the test and brake inverters } \\
\text { Data acquisition from the transducers (electrical, thermal } \\
\text { and mechanical) }\end{array}$ \\
\hline $\begin{array}{l}\text { Custom test } \\
\text { inverter }\end{array}$ & $\begin{array}{l}\text { SiC MOSFET based (up to } 100 \mathrm{kHz} \text { PWM carrier } \\
\text { frequency, max } 3 \mathrm{kHz} \text { output frequency) } \\
\text { User selectable } \mathrm{dV} / \mathrm{dt} \text { for the PWM commutations } \\
\text { Safety interlocks (hardware) } \\
\text { Common DC Bus with the Brake inverter (regenerative } \\
\text { configuration) }\end{array}$ \\
\hline
\end{tabular}

\begin{tabular}{|c|c|c|}
\hline $\begin{array}{l}\text { Measured } \\
\text { Quantity }\end{array}$ & Transducer description & $\begin{array}{c}\text { Sample } \\
\text { Frequency }\end{array}$ \\
\hline $\begin{array}{l}\text { MUT } \\
\text { Temperature }\end{array}$ & K type thermocouples & $1 \mathrm{~S} / \mathrm{s}$ \\
\hline MUT Vibration & $\begin{array}{l}\text { IEPE Piezoelectric accelerometers } \\
\pm 50 \mathrm{~g} 100 \mathrm{mv} / \mathrm{g} 0,5 \mathrm{~Hz}-10 \mathrm{kHz}\end{array}$ & $50 \mathrm{kS} / \mathrm{s}$ \\
\hline Torque & Flange torque meter $\pm 50 \mathrm{Nm}$ & $50 \mathrm{kS} / \mathrm{s}$ \\
\hline Speed & Torque meter integrated encoder & $50 \mathrm{kS} / \mathrm{s}$ \\
\hline MUT Currents* & $\begin{array}{l}\text { Wide bandwidth shunts 100Arms, } \\
\text { 1000Apk }\end{array}$ & $2 \mathrm{MS} / \mathrm{s}$ \\
\hline MUT Voltages* & $\begin{array}{l}\text { Insulated differential probe } \pm 1000 \mathrm{~V} \\
\mathrm{DC}-100 \mathrm{MHz}\end{array}$ & $2 \mathrm{MS} / \mathrm{s}$ \\
\hline DC bus Current* & Shunt / Hall effect 150A & $2 \mathrm{MS} / \mathrm{s}$ \\
\hline DC bus Voltage* & $\begin{array}{l}\text { Insulated differential probe } \pm 1000 \mathrm{~V} \\
\text { DC - } 100 \mathrm{MHz}\end{array}$ & $2 \mathrm{MS} / \mathrm{s}$ \\
\hline
\end{tabular}

* Galvanic insulation between channels required

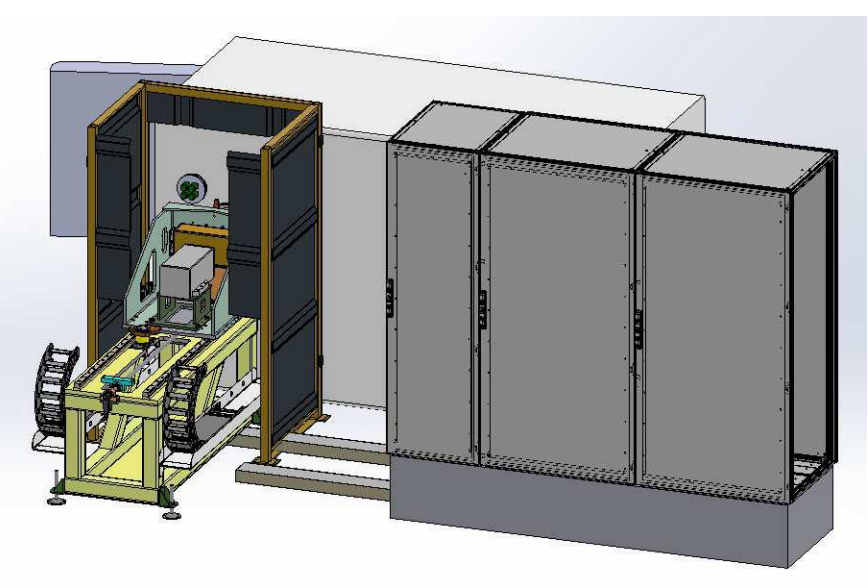

Fig. 5 Complete design of the test rig - MUT test bench inserted in the thermal vacuum chamber.

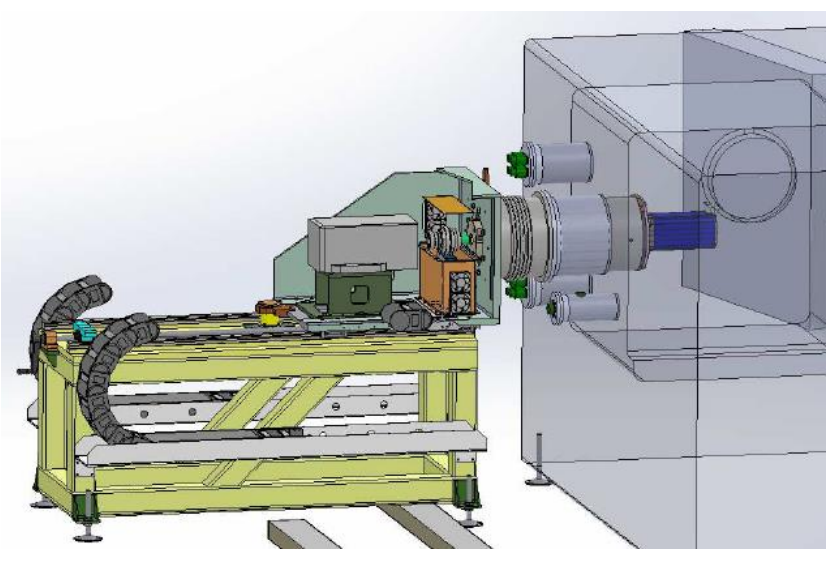

Fig. 6 Side view detail of the test bench and chamber interface.

With reference to Fig. 4, the data acquisition and control unit (9) will collect all the data from the transducers (3) and permit the control of the thermal vacuum chamber, the MUT and the brake inverters, allowing an easy configuration of the system operating parameters. Table III summarizes the specifications of the data acquisition system. The test rig adopts a hybrid data acquisition system: all the electromechanical quantities are acquired and processed by a Power analyzer to obtain RMS quantities, electrical, mechanical power and electromechanical efficiency. Temperature and vibration data are acquired by a NI cRIO system. A $100 \mathrm{MHz}$ digital oscilloscope is employed to capture voltage waveforms, to assess the rising edges of the PWM modulation.

As mentioned above, a main objective of the test setup is to project electrical motors and drives for aerospace applications to a higher level of maturity (TRL) and applicability. Due to this and time constraints, it was felt that PD measurement processes were not critical for the objectives at hand, in the first design. However, the back-ground facilities for PD probe equipment is already incorporated into the test rig design, such that PD measurements can be quite easily implemented, 
allowing for on-line measurement of deterioration of the insulation layer of the windings is to be performed, [25].

\section{B. Custom MUT Converter Design}

In Fig. 7 is reported the electrical layout of the test-rig. The system is connected to three-phase mains (400Vrms@50 Hz) throughout a Common Mode filter, and a bridge rectifier effects the AC/DC conversion. The MUT custom inverter and the brake inverter are connected to the same DC link to allow for regenerative operation and reduce power losses. The custom inverter is specifically designed to perform test with different $\mathrm{dv} / \mathrm{dt}$ ratio of the PWM motor supply voltage, and it is not intended for heavy duty operation, e.g. endurance tests of the MUT or overload test procedures, where the motor is supplied with currents exceeding the nameplate value. When endurance/overload tests are performed, a second commercial inverter (dotted in Fig. 7) must be substituted to the MUT custom inverter, and connected to the common DC link and to the MUT. The custom MUT inverter and the commercial MUT inverter cannot be connected simultaneously to the MUT.

The custom inverter, driving the motor under test MUT, is based on $\mathrm{SiC}$ power devices and capable to apply PWM commutation of different $\mathrm{dv} / \mathrm{dt}$ ratio. The adoption of SiliconCarbide power devices allows to reach both a high PWM carrier frequency and fast rise and fall time of the inverter output voltage [26]. In this way, it is possible to vary the electrical stress intensity that the MUT has to withstand, and performing tests considering different levels of electrical stimulation.

The prototype MUT converter consists of six different pcb boards, as highlighted in Fig. 8:

- A Dc link power Board

- A Power Supply Board

- A Logic Board

- Gate driver Boards

- A Signal Conditioning Board

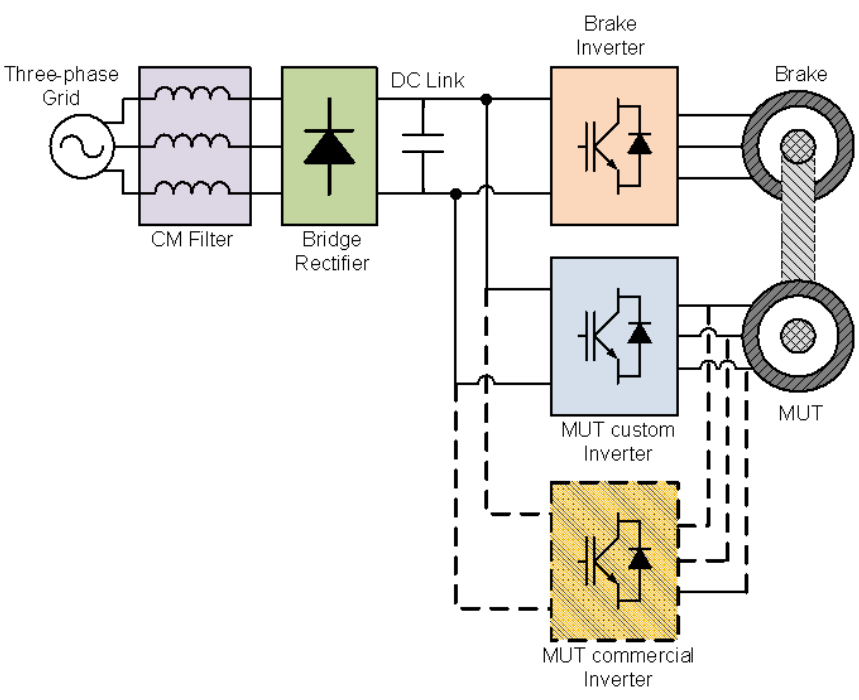

Fig. 7 Electrical Schematic of the test-rig.
- Communication Boards

The DC link board was designed to respect the constraint of maximum current rating and to minimize the stray parameters that could affect the converter behaviour at high switching frequency. The Power Supply Boards generates all the voltage needed to the circuit, whereas the Logic Board embedded a DSP that realize the control of the Motor Under Test. The Signal Conditioning Board realizes the ADC conversion and conditioning of the data and interfaces the Logic Board with the others.

The Communication Boards is for the transmission and receiving of the data between the MUT converter and the DAQ system by means of a standardized communication protocol for industrial environment (Modbus protocol).

The Gate Driver Boards are the most important part of the circuit as they permit to realize the $\mathrm{dv} / \mathrm{dt}$ ratio variation of the converter output voltage.

Traditional gate/base driver circuits are not suitable for fully exploiting the benefits and high performance of $\mathrm{SiC}$ devices in power converters. Wide-bandgap devices allow very fast switching, thus enabling system cost and size reduction, but this advantage can become a drawback if the electro-magnetic interference (EMI) behavior of the switching device is not controlled

Increasing switching speed also makes the system more susceptible to parasitic components and related effects (e.g. the Miller effect in bridge converter topologies).

The desired gate driver must be able to adapt the dv/dt ratio of the synthesized voltage, but keeping the electromagnetic interference EMI under compliance levels, guaranteeing galvanic insulation with a negligible propagation delay of the control signal even at high frequency commutation. A block scheme of the gate driver circuit is

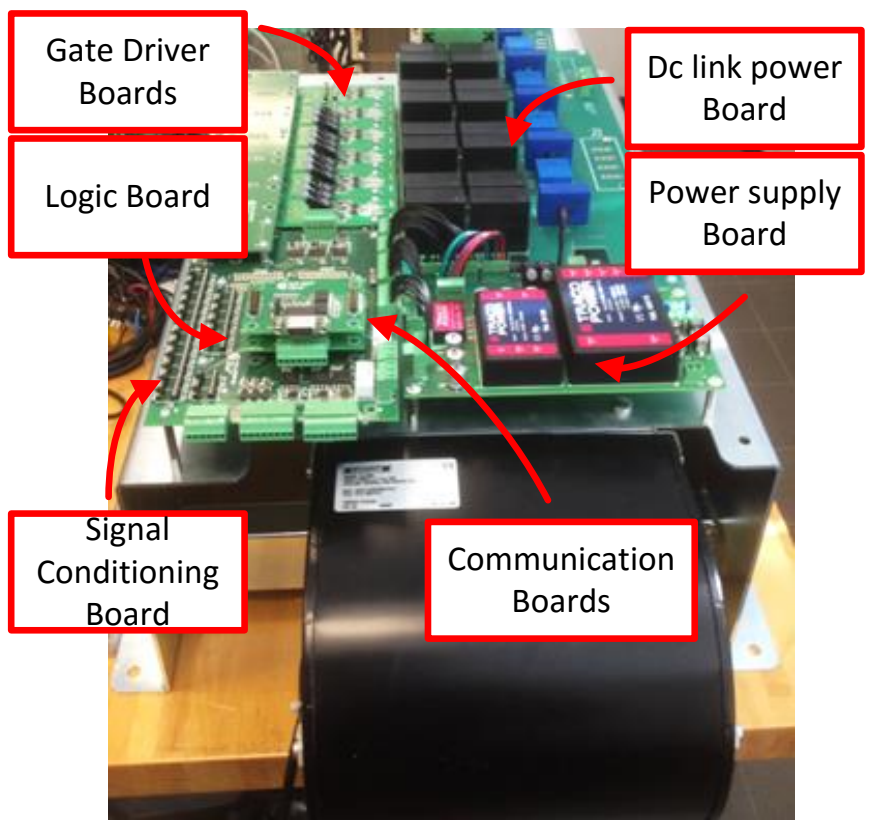

Fig. 8 Custom MUT converter Prototype. 


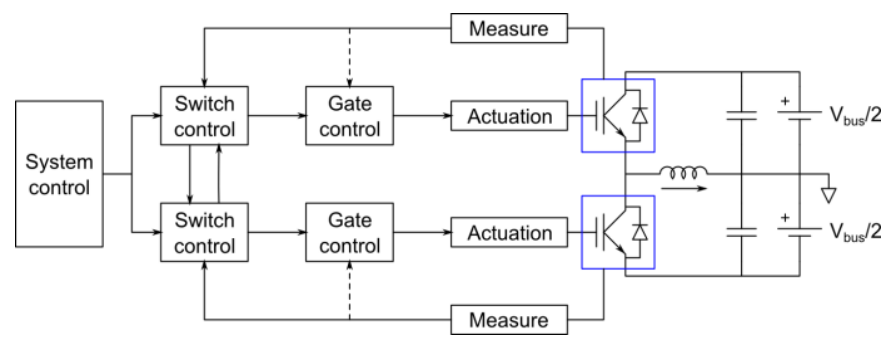

Fig. 9 Modular driver system for a power half-bridge, employing widebandgap power devices.

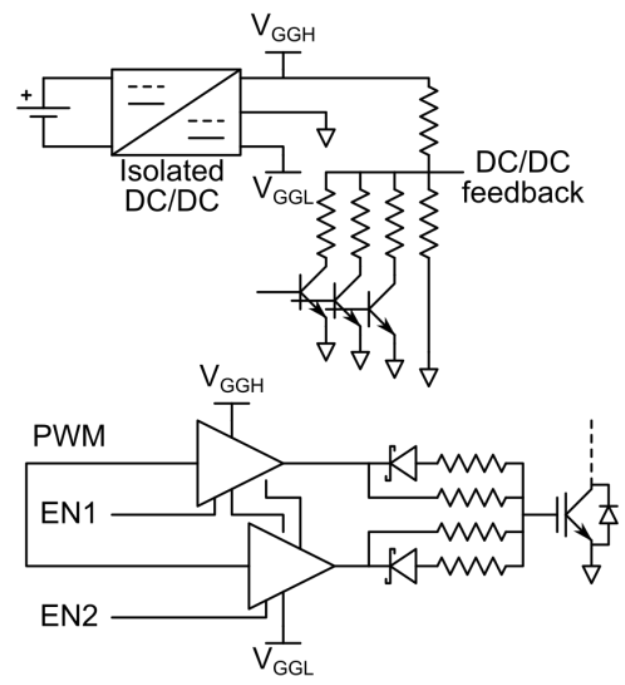

Fig. 10 gate driver schematic

shown in Fig. 9. In general gate driver circuits can be grouped in two broad categories: closed-loop topologies, where measurements of drain-source voltage, drain current or gatesource voltage are used to get information regarding the device state and accordingly changing the gate signal, or openloop topologies, where there is no explicit measurement of the controlled quantities.

Open-loop control strategies are widely used in industrial application due to the simplicity and robustness of the circuit.

What is usually done in standard drivers to partially control voltage and current waveforms during switching transients is changing the gate resistance. This is obviously a very simple yet effective technique, since no special components are needed, but drain current and voltage are very sensitive to gate voltage variations.

Some schemes provide different resistances for power device switch-on and switch-off, using diodes. This concept can be expanded, providing an array of resistors that are actively commutated; through parallel and series connection, even more resistance values can be obtained.

When the relation between commutation time and external gate resistor is known, the desired transition can be obtained through a particular combination of resistors, thus providing a more flexible control of the power device, with respect to the simple case of diode switched gate resistors.
Another way to control switching devices is through gate current control. In this case current is supply to the device gate terminal by a controlled current generator, with a saturated voltage output.

The main drawback of this control is the limited linearity: when an insulated gate device is driven by a constant current on its gate, its voltage and current transitions can hardly have linear shapes in time. This implies that some undesired harmonic content can appear, even when the time constraints of voltage or current transition are met.

Since the converter has to generate PWM voltage with 3 different possible value of $\mathrm{dv} / \mathrm{dt}$ ratio an open loop solution with variable gate resistance was chosen for the project.

A scheme of the gate driver is shown in Fig. 10 where two ultrafast Mosfet drivers with enable signals, by IXYS, act in parallel on the same $\mathrm{SiC}$ power Mosfet.

The two Mosfet drivers supply gate resistors $\mathrm{Rg}$ with different value and connected to the same power Mosfet. By means of the enable signals it is possible to choose which gate driver will trigger the power switching, making them working singularly of in conjunction. Thus, it is possible to choose up to three different equivalent value of $\mathrm{Rg}$ and therefore three different $\mathrm{dv} / \mathrm{dt}$ ratio of the MUT converter output voltage.

Furthermore, with reference to gate driver diagram of Fig. 10 , the gate driver power supply voltage (V_GGH) is generated by a DC/DC converter that provides a regulated output voltage through a feed-back control loop. The feedback network is modified by resistors switched by open-collector transistors, shown in Fig. 10, thus providing up to 8 different values of V_GGH. The variation of V_GGH affects the commutation time and provides a slight wider range for the $\mathrm{dv} / \mathrm{dt}$ ratio of the MUT converter output voltage respect to the case when only $\mathrm{Rg}$ changes, thus enabling a fine tuning of the $\mathrm{dv} / \mathrm{dt}$ ratio desired.

Considering the possible combination of the enabling signals, three possible gate resistor values can be selected, providing three different $\mathrm{dv} / \mathrm{dt}$ ratio: $4.0-2.8-2.0 \mathrm{kV} / \mu \mathrm{s}$.

The MUT custom inverter characteristics are reported in TABLE IV. and TABLE V. , that resume electrical, protection and control specifications.

TABLE IV. MUT CUSTOM INVERTER ELECTRICAL SPECIFICATIONS

\begin{tabular}{|c|c|}
\hline Input Voltage & \multicolumn{1}{|c|}{$\begin{array}{c}\text { Nominal 550 V DC } \pm 20 \% \\
\text { Maximum 800 V DC }\end{array}$} \\
\hline Carrier Frequency & \multicolumn{1}{|c|}{ Up to $100 \mathrm{kHz}$} \\
\hline Output Frequency & 0 to $3000 \mathrm{~Hz}$ (Open-loop) \\
\hline Output Speed & 0 to 20,000 rpm (Closed-loop) \\
\hline Control Mode & $\begin{array}{l}\text { Closed-loop vector control, } \\
\text { Open-loop vector control, } \\
\text { Open-loop V/Hz control } \\
\text { Initial alignment procedure for new MUT } \\
\text { installation }\end{array}$ \\
\hline
\end{tabular}


TABLE V. MUT CUSTOM INVERTER PROTECTION SPECIFICATIONS

\begin{tabular}{|c|c|}
\hline $\begin{array}{c}\text { DC Bus } \\
\text { Undervoltage }\end{array}$ & $400 \mathrm{~V}$ \\
\hline DC Bus Overvoltage & $800 \mathrm{~V}$ \\
\hline Drive Overload Trip & $\begin{array}{c}\text { Current overload value is exceeded, Programmable } \\
\text { value from GUI }\end{array}$ \\
\hline $\begin{array}{l}\text { Instantaneous } \\
\text { Overcurrent Trip }\end{array}$ & $225 \%$ of drive rated current \\
\hline Short Circuit Trip & Protects against short-leg fault \\
\hline $\begin{array}{l}\text { Overtemperature } \\
\text { Trip } \\
\end{array}$ & Drive heatsink exciding maximum temperature \\
\hline Motor Thermal Trip & $\begin{array}{l}\text { Electronically protects the motor from overheating } \\
\text { due to loading conditions }\end{array}$ \\
\hline Interlock HW trip & $\begin{array}{l}\text { Protect the converter in case of security HW shut } \\
\text { down command }\end{array}$ \\
\hline
\end{tabular}

\section{PRELIMINARY EXPERIMENTAL RESULTS}

In this section, the preliminary experimental results for system qualification are reported and discussed.

\section{A. Custom MUT Converter}

The MUT custom converter was tested on a specimen Electrical Motor used for aerospace applications.

In Fig. 11 the gate driver output voltages in function of the variation of the Rg are shown. As can be observed, the fastest commutation happens when both gate drivers are enabled and acted in parallel, whereas when the gate driver operates singularly the commutation is slower and, since the resistors $\mathrm{Rg}$ at the output of the drivers are different, two different commutation speed can be individuated.

Fig. 12 shows the gate driver waveforms when the two gate drivers acted in parallel but with different values of the gate driver power supply voltage (V_GGH).

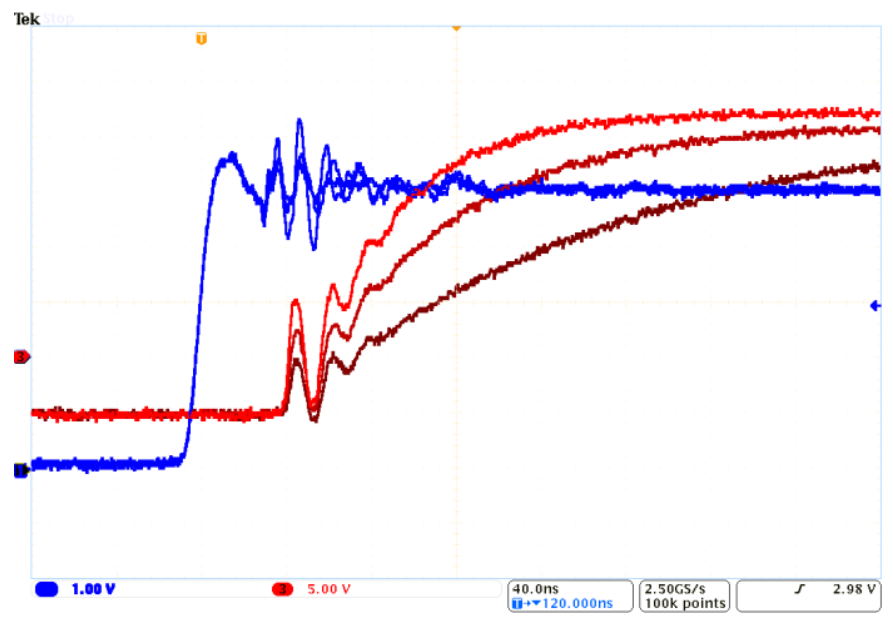

Fig. 11 Gate Driver waveforms for different commanded values of gate resistance. In blue gate driver set-point signal, while the gate driver outputs at variation of the $\mathrm{Rg}$ value are in different shades of red.

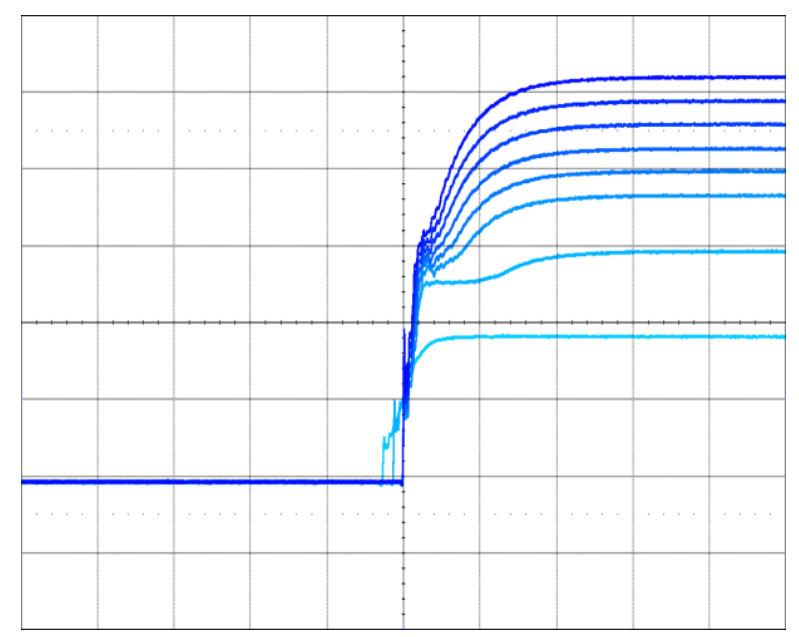

Fig. 12 gate driver waveforms when the two gate drivers acted in parallel but with 8 different values of the gate driver power supply voltage. Vgs $5 \mathrm{~V} / \mathrm{div}$, time 100 ns/div.

\section{B. Test bench and Thermal Vacuum Chamber}

The Electrical cabinets, containing the mains switchgear, MUT custom inverter and industrial inverters, operating in regenerative configuration, is shown in Fig. 13, whereas Fig 14 depicts the main selection panel user interface.

The test rig is fitted with a data acquisition system to monitor and log relevant operating parameters of the MUT during test runs.

The control interface was developed using NI Lab VIEW, as it is a commonly recognized programming environment for acquiring and manipulating engineering and scientific technical data. This allows for a flexible, custom user interface to display live data, manage operator inputs and data log operations. More in detail, the interface purpose is to:

- Control of the test inverter set points (MODBUS RTU 485)

- Control of the brake inverter set points (MODBUS RTU 485)

- Manage and display data acquisition from the transducers/instruments (electrical, thermal and mechanical)

- Manage and display data acquisition of thermal vacuum chamber environmental parameters

- Schedule and manage datalog operation for the acquired variables

Preliminary tests on the thermal vacuum chamber shown in Fig. 15 and 16 demonstrate that the performance meets or exceeds those set up in the design phase. Fig. 16 shows a thermal cycle when a thermal load equal to $5 \mathrm{~kW}$, placed inside the chamber, was connected for tests pressures higher than $300 \mathrm{mBar}$. The tests show that the proposed system performs well, especially for the heat dissipation capability, allowing for the future characterization of entire drive units (motor + converter) in the thermal vacuum chamber without risks of overheating. 


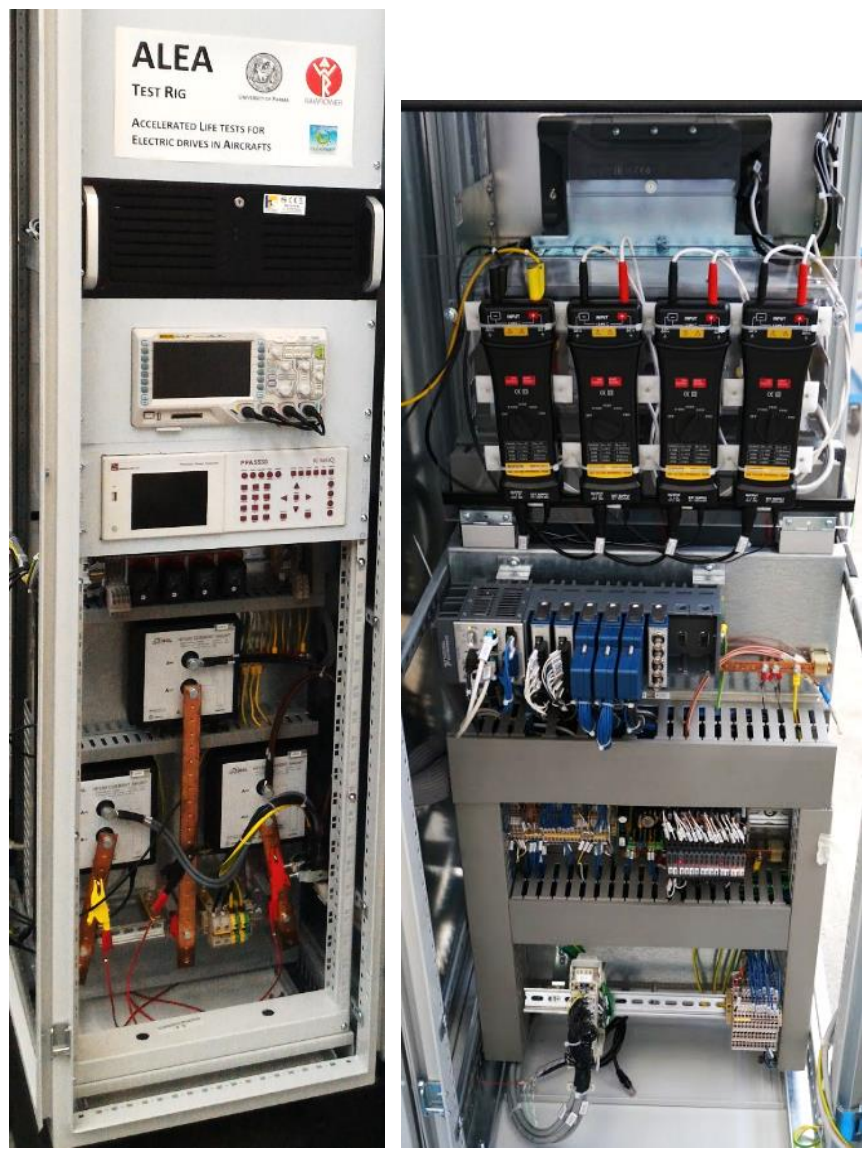

Fig. 13 Front view and internal view of the DAQ electrical cabinet.

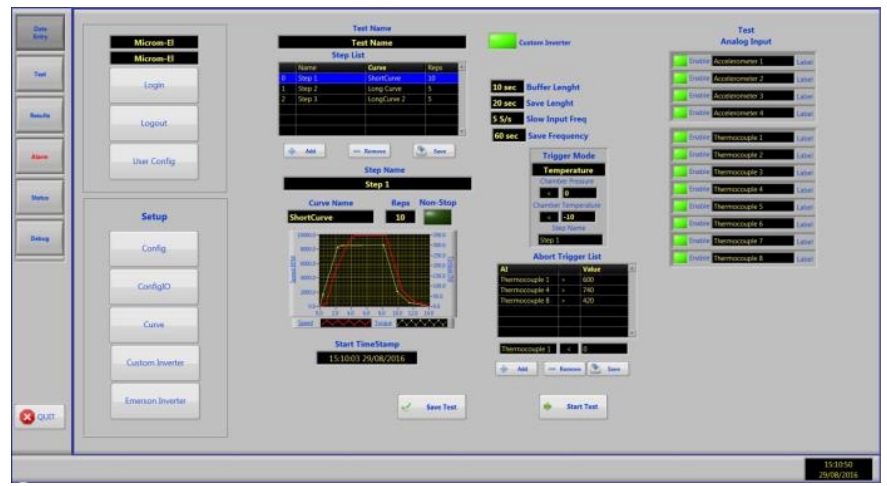

Fig. 14 Control interface data entry panel.

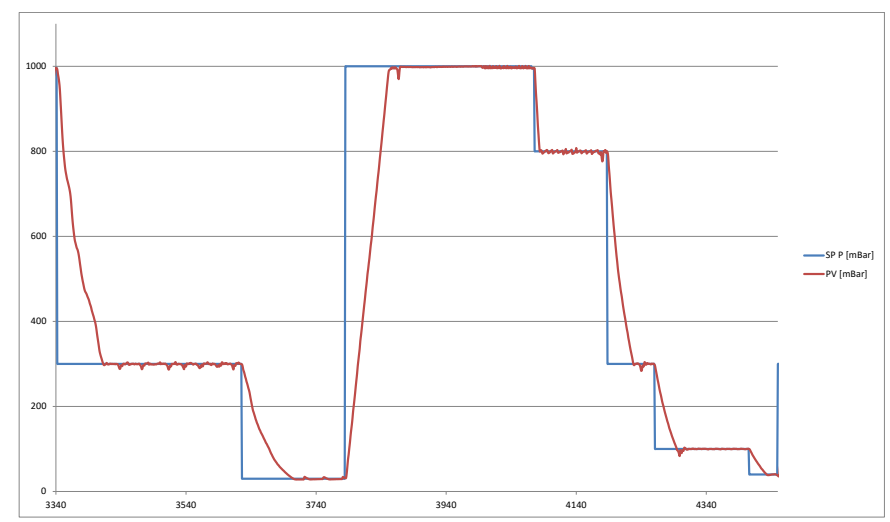

Fig. 15 Thermal vacuum chamber pressure cycles to simulate altitude operation Pressure Cycles: blue, set-point; red, measured pressure

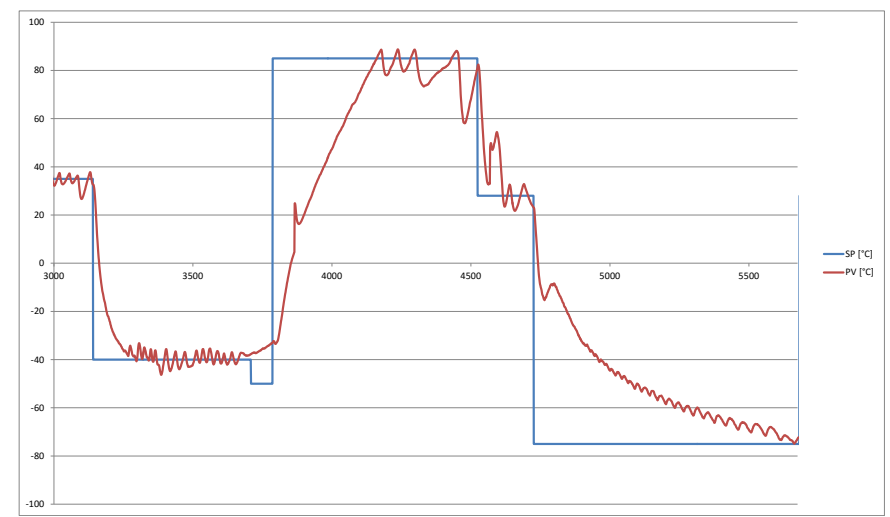

Fig. 16 Thermal vacuum chamber thermal Cycles with a $5 \mathrm{~kW}$ active thermal load inside the chamber: blue, setpoint; red, measured temperature.

\section{CONCLUSIONS AND FUTURE WORK}

This work describes methods and facilities aimed to investigate and accurately describe potential sources of failure and life time consumption models in electric machines that can be used in the MEA applications, where strict requirements in terms of reliability and fault tolerance exists.

The proposed test setup is able to reproduce a number of environmental and operational conditions to which electric drives and motors, used in aerospace applications, are subjected. It comprises a Thermal vacuum chamber, an embedded brake system and a custom inverter based on $\mathrm{SiC}$ devices. With the proposed test setup, it is possible to apply different stress factors (thermal, electrical, ambient and mechanical) singularly, or by choosing a combination of stress factors characteristic of a particular mission profile, in order to evaluate the impact of each stress factor and how the correlation between them effects electrical motors aging.

It is thus possible to tailor the test cycle in order to mimic the working cycle of an electrical motor during real operation in aircraft application.

Currently no such test rig is available on the market. Available facilities typically are able to reproduce stress factors individually (usually off-line). To the authors' 
knowledge, an on-line, 'in-the-loop', comprehensive multistress platform is not currently available. This highlights the innovation content and research potential of the proposed test setup, which will impact future definitions of standard test procedures and test equipment dedicated to aerospace components qualification.

The experimental data obtained will be used to build and to validate lifetime degradation models for electric machine in aerospace applications. Design of Experiment (DOE) has been regarded as the most suited method to assess predictive-life modelling of the electric machine insulation.

\section{ACKNOWLEGEMENTS}

This work is carried out under the funding of the EU Clean Sky Joint Undertaking, in the framework of the Clean Sky call SP1-JTI-CS-2013-03 (topic: SGO-02-088) with the proposal no. 641496: ALEA - Accelerated Life tests for Electrical drives in Aircraft.

\section{REFERENCES}

[1] Balaban, E.; Bansal, P.; Stoelting, P.; Saxena, A.; Goebel, K.F.; Curran, S., "A diagnostic approach for electro-mechanical actuators in aerospace systems," Aerospace conference, 2009 IEEE , pp.1,13, 7-14 March 2009

[2] Immovilli, F.; Bianchini, C.; Cocconcelli, M.; Bellini, A.; Rubini, R., "Bearing Fault Model for Induction Motor With Externally Induced Vibration," Industrial Electronics, IEEE Transactions on , vol.60, no.8, pp.3408,3418, Aug. 2013

[3] M. G. Pecht and F. R. Nash, "Predicting the reliability of electronic equipment,” Proc. IEEE, vol. 82, no. 7, pp. 992-1004, Jul. 1994.

[4] K. Chatterjee, M. Modarres, and J. B. Bernstein, "Fifty years of physics of failure,” J. Rel. Inf. Anal. Center, vol. 20, no. 1, pp. 1-5, Jan. 2012.

[5] Huai Wang; Liserre, M.; Blaabjerg, F.; de Place Rimmen, P.; Jacobsen, J.B.; Kvisgaard, T.; Landkildehus, J., "Transitioning to Physics-ofFailure as a Reliability Driver in Power Electronics," Emerging and Selected Topics in Power Electronics, IEEE Journal of , vol.2, no.1, pp.97,114, March 2014.

[6] M. Pecht and A. Dasgupta, "Physics-of-failure: An approach to reliable product development," in Proc. Int. Integr. Rel. Workshop, Oct. 1995, pp. $1-4$

[7] Physics of Failure Reliability Predictions, VMEbus International Trade Association, Standard ANSI/VITA 51.2, 2011.

[8] Immovilli, F.; Bianchini, C.; Bellini, A.; Sala, A., "A test bench for accelerated thermal ageing of III-V concentration solar cells using forward bias injection," Energy Conversion Congress and Exposition (ECCE), 2011 IEEE , vol., no., pp.14,19, 17-22 Sept. 2011

[9] Huai Wang; Liserre, M.; Blaabjerg, F.; de Place Rimmen, P.; Jacobsen, J.B.; Kvisgaard, T.; Landkildehus, J., "Transitioning to Physics-ofFailure as a Reliability Driver in Power Electronics," Emerging and Selected Topics in Power Electronics, IEEE Journal of , vol.2, no.1, pp.97,114, March 2014

[10] Paoletti, G.; Golubev, A., "Partial discharge theory and applications to electrical systems," Pulp and Paper, 1999. Industry Technical Conference Record of 1999 Annual, vol., no., pp.124,138, 21-25 June 1999

[11] Immovilli, F.; Bianchini, C.; Lorenzani, E.; Bellini, A.; Fornasiero, E., "Evaluation of Combined Reference Frame Transformation for Interturn Fault Detection in Permanent-Magnet Multiphase Machines," Industrial
Electronics, IEEE Transactions on , vol.62, no.3, pp.1912,1920, March 2015

[12] D. Barater et al., "Multistress characterization of insulation aging mechanisms in aerospace electric actuators," 2015 IEEE Energy Conversion Congress and Exposition (ECCE), Montreal, QC, 2015, pp. 2215-2222. doi: 10.1109/ECCE.2015.7309972

[13] Greg C. Stone, Ian Culbert, Edward A. Boulter, Hussein Dhirani, "Electrical Insulation for Rotating Machines: Design, Evaluation, Aging, Testing, and Repair," 672 pages, August 2014, Wiley-IEEE Press, ISBN: 978-1-118-05706-3

[14] IEC Standard 60610 - Principal Aspects of Functional Evaluation of Electrical Insulation Systems: Aging Mechanisms and Diagnostic Procedures

[15] Kokko, V.I.J., "Electrical ageing in lifetime estimation of hydroelectric generator stator windings," Electrical Machines (ICEM), 2010 XIX International Conference on , vol., no., pp.1,5, 6-8 Sept. 2010

[16] Zoeller, C.; Winter, Th.; Wolbank, Th.M.; Vogelsberger, M.A.; and Bazant, M.; "Separation of Fundamental Wave and Transient Components of the Current Signal for Machine Insulation State Monitoring” IECON 2014 - 40th Annual Conference on IEEE Industrial Electronics Society, Oct. 2014

[17] Rui Rui; Cotton I., "Impact of low pressure aerospace environment on machine winding insulation," Electrical Insulation (ISEI), Conference Record of the 2010 IEEE International Symposium on , vol., no., pp.1,5, 6-9 June 2010

[18] Fernando, M.A.R.M.; Naranpanawa, W.M.L.B.; Rathnayake, R.M.H.M.; Jayantha, G.A., "Condition assessment of stator insulation during drying, wetting and electrical ageing," Dielectrics and Electrical Insulation, IEEE Transactions on , vol.20, no.6, pp.2081,2090, December 2013

[19] M. Galea, C. Gerada, T. Raminosoa, and P. Wheeler, "A Thermal Improvement Technique for the Phase Windings of Electrical Machines," Industry Applications, IEEE Transactions on, vol. 48, pp. 79-87, 2012.

[20] Farahani, M.; Gockenbach, E.; Borsi, H.; Schäfer, K.; Kaufhold, M., "Behavior of machine insulation systems subjected to accelerated thermal aging test," Dielectrics and Electrical Insulation, IEEE Transactions on , vol.17, no.5, pp.1364,1372, October 2010

[21] M. Galea, L. Papini, H. Zhang, C. Gerada, and T. Hamiti, "Demagnetisation Analysis for Halbach Array Configurations in Electrical Machines," Magnetics, IEEE Transactions on, vol. PP, pp. 1$1,2015$.

[22] Morin, R.A.; Bartnikas, R., "Multistress Aging of Stator Bars in a ThreePhase Model Stator Under Load Cycling Conditions," Energy Conversion, IEEE Transactions on , vol.27, no.2, pp.374,381, June 2012

[23] C. Sciascera, M. Galea, P. Giangrande, C. Gerada, "Lifetime Consumption and Degradation Analysis of the Winding Insulation of Electrical Machines", Power Electronics, Machines and Drives (PEMD 2016), 8th IET International Conference on, Glasgow, 2016, pp. 1-5.

[24] Lahoud, N.; Faucher, J.; Malec, D.; Maussion, P., "Electrical Aging of the Insulation of Low-Voltage Machines: Model Definition and Test With the Design of Experiments," Industrial Electronics, IEEE Transactions on , vol.60, no.9, pp.4147,4155, Sept. 2013

[25] Barater, D.; Pietrini, G.; Franceschini, G.; Mancinelli, P.; Cavallini, A., "An open problem for More Electrical Aircraft (MEA): how insulation systems of actuators can be qualified?," 2016 IEEE Energy Conversion Congress and Exposition (ECCE), Milwaukee, WI, 18-22 Sept. 2016

[26] D. Barater, C. Concari, G. Buticchi, E. Gurpinar, D. De and A. Castellazzi, "Performance Evaluation of a Three-Level ANPC Photovoltaic Grid-Connected Inverter With 650-V SiC Devices and Optimized PWM," in IEEE Transactions on Industry Applications, vol. 52, no. 3, pp. 2475-2485, May-June 2016. doi: 10.1109/TIA.2016.2514344 